\title{
O que Chamamos de Saúde Coletiva Atualmente? $\left.{ }^{*}\right)$
}

\author{
WE CALL COLLECTIVE HEALTH CURRENTLY?
}

Edmundo Granda(**)

\section{RESUMO}

O autor delineia o quadro de crise da saúde pública convencional e ilustra sua debilidade destacando, dentre outros pontos, sua perda de identidade (reduzida a ações parciais), a incapacidade de promoção e proteção da saúde, a valorização do aspecto lucrativo. Ressalta a necessidade de alteração do paradigma, que consiste na superação da visão tecnicista, e a busca de fundamento para uma proposta alternativa. A partir dessas colocações, dispõe sobre a construção de uma saúde pública alternativa compreendida historicamente. Assim, haveria o estabelecimento de uma nova forma de ver, conhecer e agir sobre o objeto problema (saúde-doença-cuidado), tendo como pano de fundo uma perspectiva espaço-temporal responsável pela relação, de dupla troca, entre a ação e a estrutura ou sistema social.

\section{Descritores}

Saúde pública, saúde pública alternativa, mudança de paradigma, contextualização.

\section{ABSTRACT}

The author draws the picture of the crisis of the conventional public health model and illustrates its debility by detaching, amongst other points,

(*) Trata-se de artigo elaborado a partir da apresentação de conferência sobre o mesmo tema no VII Congresso Brasileiro de Saúde Coletiva, realizado em Brasilia, entre 29 de julho e 2 de agosto de 2003.

(**) Professor da Universidad Nacional de Loja e Profissional Nacional de Recursos Humanos da Organização Panamericana de Saúde - Equador. E-mail: egranda@ecu.ops-oms.org. 
its loss of identity (reduced to partial actions), the incapacity of promoting and protecting health, and the overvaluation of its lucrative aspect. He stands out the necessity of changing the paradigm, to overcome the technicist vision, and to search for an alternative proposal. Then, he proposes the "historical" construction of an alternative public health, so that a new way of seeing, knowing and acting on the object (health-illnesscare) could be established, based on a time/space perspective responsible for the relationship, of double exchange, between the action and the structure or social system

\section{Key words}

Public health, alternative public health, change of paradigm, contextualização.

\section{UNL/OPS (1)}

Um primeiro elemento, necessário para a construção de um pensamento e uma prática de acordo com as necessidades de saúde da população - chame-se ela saúde coletiva, ou saúde pública alternativa, ou medicina social radical - está na necessidade de compreendê-la como história, buscando no passado e no presente, suas potencialidades e suas limitações. Mario Testa em sua obra "Pensar em Saúde" nos diz: "...si solo la historia puede conducir a una ciencia verdadera, una ciencia verdadera tiene que servir para la construcción de la historia(2)". Considero que uma contribuição importante da Medicina Social Latino-americana e da saúde coletiva, tenha sido essa preocupação por compreender a forma como foram-se constituindo as categorias e as práticas neste campo, o que tem possibilitado superar a visão tecnicista da saúde pública tradicional e fundamentar uma proposta de saúde coletiva contextualizada. Esta é uma segunda caracteristica que acompanha o trabalho alternativo desenvolvido na área, isto é, a tentativa de construir uma proposta cientifica contextualizada, que interpreta que a saúde pública como teoria e prática é parte de um todo.

No início da década de 90, a Universidade Nacional de Loja se uniu ao esforço latino-americano para indagar o passado, com vista a dar resposta à "Crise da saúde pública", que havia sido definida como "incapacidad de la mayoría de sociedades para promover y proteger su salud en la medida que sus circunstancias históricas requieren ${ }^{(3)}$, e interpretou que a saúde pública no Equador havia perdido sua identidade, ficando reduzida a uma coleção de ações parciais, desordenadas e ineficazes, desenvolvi-

(1) Comunicação pessoal.

(2) TESTA, Mario. Pensar en Salud. Buenos Aires: Lugar Editorial. 1993.

(3) ORGANIZACIÓN PANAMERICANA DE LA SALUD. La Crisis de la Salud Pública. Washington D. C.: OPS/OMS, 1993. 
das por um Estado que se retirava de suas obrigações sociais. Como prática social haviam subsistido algumas forças que desenvolveram importantes propostas, algumas delas exitosas, enquanto o mercado havia fixado sua atenção unicamente na possibilidade de transformar a gerência dos serviços de atenção à doença, em boas perspectivas de acumulação de capital, deixando de lado a prevenção de enfermidades e a promoção da saúde, por seu caráter não rentável. No plano disciplinar, a saúde pública adotava várias faces: em alguns momentos aparecia como um acordo estabelecido de idéias precariamente alinhavadas, que respondia a propostas funcionalistas, úteis para o Estado e para o mercado; em algumas ocasiões também se propunha a conversar com o mundo da vida, sem conseguir entendê-lo, e balbuciava algumas propostas nem sempre coerentes, enquanto, em outras ocasiões adotava afetação cientificista. De todas as maneiras, também se visualizava avanços disciplinares, impulsionados por alguns centros de educação superior que tentavam alinhavar aproximações mais abrangentes e contextualizadas. Em resumo, pensávamos que a Saúde Pública já não era o que havia sido, mas tampouco chegava a ser outra, e sim que se mantinha numa situação um tanto amorfa.

Ao olhar para o início do século XX, podemos definir algumas características da Saúde Pública convencional, às que denominamos de Enfermologia Pública ${ }^{(4)}$, quais sejam: o pressuposto filosófico-teórico da enfermidade e da morte como ponto de partida para a explicação da saúde; o método positivista para explicar o risco de adoecer na população e o estrututral-funcionalismo para compreender a realidade social; e o reconhecimento do poder do Estado, como força privilegiada para assegurar a prevenção de doenças. A nosso ver, estas características filosóficas, teóricas e práticas da saúde pública convencional, explicam seus pontos fortes e suas debilidades, definem os âmbitos de crítica e dão luzes para propor sua mudança. Não pretendemos dizer que tais caracteristicas têm estado sempre presentes na Saúde Pública, mas que elas tiveram maior força durante o século, opondo-se a outras propostas, por exemplo, àquela gerada pelo movimento europeu da Medicina Social, que reconhecia que a participação política geradora de democracia, fraternidade e igualdade era a principal força para transformar a situação de saúde da população(5). Similares aspirações foram reinstaladas nas décadas de sessenta e oitenta na América Latina, com o movimento da Medicina Social. O movimento europeu deixou como resultado, um rico arsenal doutrinário e ideológico, que não foi integrado pela "Enfermologia Pública". Tampouco o movimento latino-americano de Medicina Social conseguiu impactar sig-

(4) GRANDA, Edmundo. La Salud Pública y las Metáforas sobre la Vida. Revista de la Facultad Nacional de Salud Pública. v. 18, n. 2, p. 83-100, jul./dic. 2001.

(5) La propuesta de Virchow consistia en una reforma social radical que, en términos generales, comprendia democracia completa e irrestricta, educación, libertad y prosperidad. En: ROSEN George. Da policia médica a medicina social. Rio de Janeiro: Ed. Graal, 1979. 
nificativamente sobre a saúde pública convencional, apesar de sua critica radical, dos conhecimentos adquiridos e de suas propostas inovadoras. Diferente sorte teve a Saúde Coletiva Brasileira, a mesma que - em meu entender - pôde impactar o pensamento e prática da saúde populacional.

Tampouco produziram grandes reformulações, as distintas propostas reconhecidas por Arouca como preventivistas ${ }^{(6)}$; ao contrário, fortaleceram esse paradigma ou metáfora ${ }^{(7)}$; refiro-me às inicitativas de mudança dos departamentos universitários de higiene pelos de medicina preventiva, às propostas de medicina comunitária forjadas nos Estados Unidos e alguns paises da América Latina, e à iniciativa de atenção primária de saúde. A permanência e relativo êxito da metáfora da Saúde Pública, baseada no tripé mencionado, possivelmente se devem à coerência entre as bases ideológicas, suas concepções e ações técnico-políticas e sua projeção sobre a sociedade.

Para compreender a Saúde Pública convencional, recordemos que a Medicina Clínica constituiu seu olhar, seu saber, seus métodos e técnicas sobre a doença e a morte. Foucault, no "Nascimento da Clínica" afirma o seguinte: "O homem ocidental não tem podido se constituir a seus próprios olhos como objeto de ciência... se não na abertura de sua própria eliminação: da experiência da sem razão nasceram todas as psicologias e a possibilidade mesma da psicologia; da integração da morte, no pensamento médico, nasceu uma medicina que se apresenta como ciência do indivíduo."(8) O "êxito" da Medicina Clínica que, sem dúvidas, tem sido bastante notório, tem dependido do alcance de sua positividade por meio de sua relação intima com a enfermidade e a morte. Desta maneira, uma boa parte dos problemas da "máquina corporal" ligados com os desarranjos de sua estrutura e função, por "causas" externas e internas, puderam ser explicados, neutralizados ou abolidos, com o que se conseguiu produzir "máquinas corporais" menos doentes e que demoram mais para morrer.

Frente ao "êxito" da Medicina Clinica sobre a doença individual, também se considerou, em principios do século $X X$, que era possivel construir uma "enfermologia social" chamada Saúde Pública, supostamente capaz de dar conta da doença coletiva ou pública, como somatória de doenças particulares. A Saúde Pública não devia encarregar-se do corpo doente que correspondia à Medicina Clínica, mas se responsabilizaria pelas causas que se encontram fora da máquina corporal. Nessa medida, a Saúde Pública poderia sair do corpo humano e encontrar as causas nos animais, plantas, coisas e relações entre individuos, que poderiam causar as doenças. A Saúde Pública ocupa então, um espaço diferente daquele que é ocupado e dominado pela Clinica, tomando a seu cargo o risco e a prevenção da doença. Ora, a Medicina Clinica tem como finalidade funda-

(6) AROUCA, Sergio. O dilema preventivista: contribuição para a compreensão e critica da medicina preventiva. Tese (doutorado) UNICAMP.

(7) PASSOS Nogueira, Roberto. Perspectivas da Qualidade em Saúde. Rio: Qualitymark, 1994.

(8) FOUCAULT, Michel. El Nacimiento de la Clinica. México: Siglo XXI, 1966, p. 276. 
mental curar e, nessa medida, aceita, ao constituir-se como disciplina científica, centrar sua preocupação sobre a enfermidade. Sem dúvidas, a doença da pessoa seria exorcizada e sua morte seria evitada por meio da intervenção sábia do pensamento e do bisturi, manejados pelo olhar e pelas mãos do médico. Mas, para a Saúde Pública o problema é mais complexo e deve responder à pergunta: Onde se encontram o pensamento e o bisturi públicos para explicar o risco e prevenir ou exorcizar a doença e morte que ocorrem nos grupos humanos? A Saúde Pública os coloca na tecnologia positivista manejada pelo Estado. Assim como a medicina transforma o médico no mago que explica a doença e que ao mesmo tempo a cura, assim também a saúde pública transforma o Estado no mago que explica o risco e o previne.

Essa metáfora do Estado mago e exorcista sobre o risco e a doença públicos, é plenamente coerente com a concepção social dominante durante o século dezenove e início do século vinte. É também coerente com as utopias reinantes naquele momento. Recorde-se que vivemos dois séculos com a idéia de que a Razão (instrumental) e o Estado nos entregariam a solução a todos os nossos problemas econômicos, sociais, políticos e culturais. Também acreditamos que a razão possibilitaria estabelecer um contrato, através do qual organizariamos um centro ou Estado Soberano, que fundado no conhecimento científico, poderia acumular todo o poder necessário para comandar a produção de bens materiais e espirituais, distribuir igualitariamente a riqueza produzida, instituir a lei, assegurar a liberdade dos individuos, brindar a felicidade a todos, e no campo da saúde, explicar os riscos, prevenir as doenças coletivas e organizar os serviços para a cura das enfermidades. ${ }^{(9)}$ Assim, a Saúde Pública organiza sua base de sustentação sobre o mencionado tripé, constituído pelo pensamento centrado em torno da doença e da morte, o método positivista ou naturalista para o cálculo do risco de ocorrência de enfermidades na população, o estrutural-funcionalismo como teoria da realidade social e a proeminência do Estado como lugar da organização das ações preventivas e apoio à gestão dos serviços de atenção médica.

Os pressupostos funcionalistas poupam a Saúde Pública da preocupação pelo sujeito individual e coletivo. É suficiente interpretá-lo como objeto individual ou objeto coletivo, que existe e se reproduz em função da estrutura ou sistema social de que é parte determinada e sobre o qual pode fazer uma aproximação naturalista ou positivista. A aproximação positivista permite chegar à realidade desses objetos através da razão tecnológica ${ }^{(10)}$ ou razão instrumenta/(11), conforme corresponda a qualquer

(9) GRANDA, Edmundo. Sujeto, Etica y Salud. Salud Pública: Experiencias y Reflexiones, n. 3, p. 46-61, 1997.

(10) AYRES, José Ricardo. Epidemiologia e Emancipação. Rio de Janeiro: Hucitec, Abrasco, pp. 67-85.

(11) HABERMAS, Jurgen. Teoria de la Acción Comunicativa. Madrid: Taurus, 1992. 
coisa ou objeto que não é autopoiético(12), quer dizer, que não gera em seu viver cotidiano nem suas normas, nem seus produtos ou seus mecanismos de reprodução. Frente a um objeto que existe como um produto das causas do passado, não é necessário compreender a ação social (que se dá aqui e agora) e, além disso, é lícito que o Estado intervenha de fora com a tecnologia científica para alcançar a saúde subtraindo a doença.

O sanitarista, então, constitui-se em um agente do Estado e da técnica: um interventor técnico-normativo, que através de suas ações busca efetivar nas instituições de atenção médica e na população, o próprio poder do Estado, e executar a verdade da ideologia cientifico-tecnológica, com o fim de prevenir os riscos de adoecer da população a seu cargo. A Saúde Pública passa a ser boa expressão de uma disciplina cientifica moderna, uma forma de ordem do mundo, e por sua vez, a doença da população é transformada em objeto da ciência, passivel de intervenção, de transformação, de modelação de "produção" (13). Por meio de sua ação interventora técnico-normativa, o sanitarista quer integrar e acumular conhecimentos, habilidades e experiência depositadas nos cânones técnico-científicos, com os quais o sanitarista pode levar a cabo o cálculo do risco; neste sentido, deve saber aplicar as metodologias de investigação positivas especificas para cada situação; apoiar a elaboração e fazer cumprir as normas determinadas pelo Estado, referentes à doença pública e às respostas sociais sobre ela organizadas; organizar, desenvolver e cuidar dos serviços encarregados de prevenir as doenças e apoiar a administração daquelas instituições destinadas a tratá-las; educar a população para que adquira os conhecimentos e técnicas que permitem calcular seus riscos, prevenir as enfermidades e, ao mesmo tempo, substituir seus saberes e práticas tradicionais (portanto irracionais e arriscados); e velar pela sistematização e desenvolvimento dos conhecimentos e normas necessários para o avanço da ciência e o fortalecimento do Estado. O sanitarista do século $X X$ está incumbido então, de cuidar da saúde do Estado e da ciência-técnica, atuando sobre o risco de adoecer da população a seu cargo; deve observar a população, mas através da lente da norma estatal e da razão instrumental; e deve intervir sobre a população transformada em objeto, a mesma que não somente deve interagir com a ciência e a técnica, como também tem, além disso, que aprender a esquecer sua cultura particular, sempre arriscada.

A construção de uma proposta alternativa no campo da saúde pública deve criticar as características anteriormente indicadas. Em outros termos, deveria estudar a potencialidade de construir uma saúde pública fundada em uma metáfora que reconhece os seguintes pressupostos: (1) o pressuposto teórico-filosófico da saúde e da vida, sem descuidar da prevenção da doença; (2) os métodos que integram diversas metáforas, e

(12) MATURANA, Humberto; VARELA, Francisco. El Árbol del Conocimiento. 9 ed. Santiago de Chile: Editorial Universitaria, 1993.

(13) LUZ, Madel. Natural, Racional, Social. Buenos Aires: Lugar Editorial, 1997, p. 32. 
propõem variadas hermenêuticas (incluindo a cientifica-positivista) capazes de dar conta da ação social e das estruturas; (3) as práticas sociais que integram diversos atores e poderes além do poder do Estado: a ação do indivíduo, dos públicos ou movimentos sociais que promovem a saúde, controlam socialmente o cumprimento dos deveres postos para o Estado, lutam por sua democratização e entram em acordos-desacordos com os poderes supra e infra-nacionais.

Uma primeira pergunta refere-se à possibilidade de que, neste momento de globalização e neoliberalismo triunfante, se caminhe nessa direção. Parece que isso é possivel, já que, cada vez mais, ouvimos que: a) não é possivel alcançar a saúde unicamente subtraindo a doença; b) a aproximação positivista e funcionalista que exclui o sujeito como gerador de seu próprio conhecimento e da ação também tem sido bastante criticada; c) O Estado, suposto mago e exorcista sobre o risco e a doença públicos, tem tido sua autonomia e soberania sobremaneira debilitadas, transformando-se em intermediário de interesses diversos e em geral contraditórios; d) novas forças sociais e políticas aparecem no horizonte; e e) importantes inovações teóricas e práticas ocorrem na ciência em geral e, particularmente, na investigação em saúde.

Esses fatos foram abordados com mais detalhamento em trabalhos anteriores ${ }^{(14)}$, recordaremos, apenas, dois elementos importantes: o Estado-nação, detentor do que fazer em saúde pública e seu principal impulsionador, tem sua autonomia e soberania debilitadas, transformandose em um intermediário, sem grande poder para definir e defender as políticas sociais no campo da saúde coletiva. Ao mesmo tempo, novos poderes têm surgido, representados pelas identidades defensivas e pró-ativas, que defendem aspectos intimamente ligados ao seu modo de vida e projetam suas ações políticas sobre outros atores e âmbitos da sociedade. Nessa medida, desde a Saúde Pública, deve-se compreender que nossa possibilidade real para apontar o fortalecimento da saúde das coletividades, o fortalecimento das instituições debilitadas e o próprio desenvolvimento de nossa disciplina está baseada na necessidade de nos transformarmos em intérpretes-mediadores dessas novas forças que surgem neste momento de globalização. Em outras palavras, o contexto social, cultural e político atual abre uma perspectiva de mudança para a Saúde Pública convencional. Ao mesmo tempo, o enfraquecimento da metáfora que sustenta a eficácia da "enfermologia pública" também reclama novas formas de olhar e agir.

\section{O OLHAR}

Dissemos anteriormente que uma primeira caracteristica das propostas alternativas sobre a saúde pública, constitui sua necessidade de

(14) GRANDA, Edmundo. Salud: globalización de la vida y de la solidaridad. Saúde em Debate. v. 24, n. 56, p. 83-101. Id. Salud pública: hacia la ampliación de la razón. In: La medicina al final del milenio. Guadalajara: Universidad de Guadalajara, 1995. 
compreendê-la historicamente. Uma segunda caracteristica, havíamos indicado, é aquela necessidade de contextualização. Uma terceira característica que acompanha as propostas de mudança baseia-se na forma de ver, conhecer e agir sobre o objeto-problema saúde-enfermidade-cuidado da população. A Saúde Pública convencional viu a população como objeto de intervenção por parte da norma funcional e da ciência positiva, enquanto que a Saúde Pública alternativa requer olhar como os sujeitos individuais e coletivos criam ou geram sua saúde na vida cotidiana e ao mesmo tempo constroem instituições para apoiar a promoção da saúde, prevenir e atender doentes. Sob essa exigência, interpretamos que o olhar da Saúde Pública alternativa está mudando e buscando ampliar seu horizonte para avançar a partir de sua preocupação em ver apenas a doença e a morte para a necessidade de refletir e entender a saúde e a vida, sem descuidar das primeiras; seu costume de ver objetos para tentar olhar as pessoas; seu compromisso com a função sanitarista do Estado para a compreensão de outras formas de agir saudáveis que, por sua vez, constroem organizações e instituições públicas para a saúde.

Para a Medicina Clínica, o saber do paciente não faz parte do conhecimento científico acumulado (a evidência) sobre a doença, nem seu livre-arbítrio participa da cura, mas, ao contrário, o individuo tem que se submeter, tanto no âmbito da compreensão quanto no agir, aos ditames do Médico, representante do conhecimento e do método científicos; desta forma, nas palavras de Foucault o individuo é suprimido, é varrido como evidência; ou como disse Madel Luz, a questão da vida... é transformada em metafísica ${ }^{(15)}$. Assim também, com a Enfermologia Pública, os coletivos têm que se submeter ao conhecimento sobre o risco sustentado pela ciência epidemiológica e nessa medida não podem jogar nenhum papel a cultura local nem as diversidades humanas historicamente constituidas, as mesmas que supostamente se renderam ante a presença civilizadora da razão e da moral. Por outro lado, as práticas necessárias para a prevenção devem ser desenhadas e executadas pelo Estado, que em seu trabalho igualmente civilizador ajudará a superar as práticas e poderes locais necessariamente irracionais; as coletividades, nas palavras de Foucault, teriam sido suprimidas ou transformadas em objetos com vida ${ }^{(16)}$.

A vida e o sujeito. Para a Saúde Pública alternativa, o anterior é profundamente contraditório porque não podem existir objetos conscientes com vida, eles são, necessariamente, sujeitos; os objetos sempre são alopoiéticos, enquanto que os seres vivos são autopoiéticos ${ }^{(17)}$, ou seja, produzem suas próprias normas e estruturas de autoprodução, especialmente as populações humanas; o viver gera a saúde e ela não acontece

(15) LUZ, Madel. Op. cit., p. 88.

(16) GRANDA, Edmundo. La Salud Pública y las Metáforas.... cit.

(17) MATURANA, Humberto; VARELA, Francisco. Op. cit. 
apenas subtraindo-se a doença, saúde é uma forma de viver autônoma e solidária, consubstancial com a cultura humana, dependente e condicionante das relações que se estabelecem com a natureza, a sociedade e o Esta$d o^{(18)}$; se em seu desenvolvimento diário, as populações produzem sua saúde, então, a força, o poder fundamental para alcançá-la encontra-se nas próprias populações e em sua vida. Não é possivel confiar unicamente no poder do Estado e no poder da ciência positiva para alcançar a saúde; se se considera que a própria vida engendra saúde, é necessário interpretar a vida por meio de lógicas recursivas e aproximações ontológicas que privilegiem o organismo como o eixo do conhecimento, a aprendizagem e a ação de mudança(19), senão ocorre o que Almeida e Silva Paim criticam: "a saúde se coloca no ponto cego das ciências da saúde". (20)

Analisemos os pontos anteriores. Se a saúde é a capacidade de autonormatizar o bom funcionamento corporal e psíquico, então poderemos falar de uma normatividade biológica comum para a espécie, mas também existirá uma normatividade cultural própria do mundo epistêmico, social, de práticas e poderes na qual a população humana aprendeu. Existirá, além disso, uma normatividade individual própria de cada pessoa, produto de sua especial história de vida, personalidade e relação com o meio ambiente. Se é assim, a Saúde Pública Alternativa começa a se perguntar sobre como proceder para transformar-se em intérprete das especiais circunstâncias particulares de vida da população, onde se encontram as maiores potencialidades de saúde. Isso está levando a Saúde Pública a pensar que o método científico positivista baseado na idéia da verdade universal através da mathesis ou comparação das coisas no mundo(21) deverá dar lugar a uma proposta metódica que também considere as verdades particulares e diversas já que a saúde ocorreria na medida em que o organismo social e o corpo humano conservam sua capacidade de instituir novas normas. Esta forma de ver torna complexos os métodos de investigação tradicionais utilizados pela epidemiologia e fundamentados numa visão de ris$\mathrm{co}$, ao se verem obrigados a diferenciar a suscetibilidade grupal e individual e a ação dos fatores associados ao problema que se pretende estudar ${ }^{(22)}$. A esse respeito, Naomar Almeida, a partir da Epidemiologia, faz contribuições importantes para dar conta desta e de outras problemáticas ao intro-

(18) Maestria de Salud Pública de la UNL 1997-1999. Plan de Estudios. Loja: Universidad Nacional de Loja, 1997.

(19) NIETZSCHE, Wiener, Von Glaserfeld, McCulloch, Von Foerster, Maturana, Heiddeger, Varela, Echeverria, Foucault, Habermas y muchos otros elaboran propuestas epistemológicas y ontológicas distintas que ofrecen alternativas interesantes para tratar esta problemática.

(20) ALMEIDA FILHO, Naomar; PAIM, J. Silva. La Crisis de la Salud Pública y el Movimiento de Salud Colectiva en Latinoamérica. Cuadernos Médico Sociales, v. 75, p. 5-30.

(21) AYRES, José Ricardo, Op. cit., v. 75, p. 5-30.

(22) CASTIEL, DAVID. O buraco e o avestruz: $A$ singularidade de adoecer humano. Campinas: Papirus, 1994, p. 158. 
duzir três dimensões: a dimensão das instâncias, a dimensão dos domínios e a dimensão dos niveis de complexidade ${ }^{(23)}$.

A Saúde Pública alternativa também está repensando o tempo de forma muito diferente de como tradicionalmente o temos pensado, isto é, em uma suposta eternidade nas leis. O interesse pela saúde e vida, e não somente da doença, recomenda mais que se pense na saúde como a capacidade de romper as normas impostas e construir novas normas sob as exigências de adaptação ao mundo em mudança ${ }^{(24)}$. A esse respeito Humberto Maturana entende que o organismo, para sobreviver, necessita se acoplar a seus especiais requerimentos organizativos, que estabelecem sua própria identidade, para o que, às vezes, tem necessidade de trocar suas relações com o meio: Todo lo que en los seres vivos ocurre no responde a especificaciones del medio, sino a sus propias determinaciones estructurales. Lo único que el medio puede hacer es 'gatillar' determinadas reacciones definidas por la estructura del ser vivo(25). A Saúde Pública Alternativa teria que necessariamente aceitar a temporalidade e, nessa medida, está compelida a entender que os cuidados requeridos para a superação da saúde não se encontram unicamente na construção de uma ciência representativa de toda a suposta verdade e num Estado ou centro intérprete e legislador de toda normatividade necessária para alcançar a saúde, senão que a ação fundamental se baseia na constante e infinita normatividade, que elabora o próprio organismo vivente em sua conjugação estrutural e consensual|(26), ação que a Saúde Pública deveria constantemente interpretar e reinterpretar.

A Saúde Pública alternativa também exige que se interprete o futuro de forma distinta da classicamente estatuída, ou seja, não pode aceitar a evolução como um fato necessário, previamente estabelecido pelas leis objetivas dentro de um universo fechado. Se a própria vida tem uma capacidade autonormativa ou autopoiética, o universo sempre é aberto, e a evolução é mais o resultado de uma evolução natural, conforme sustentam Varela e Maturana (27), enquanto a sociedade parece seguir "un camino más allá de la gente y que es necesario deshacerse de esa idea de una dirección consciente y de un total dominio sobre nuestro destino, tal como

(23) ALMEIDA FILHO, Naomar. La ciencia tímida: ensayos de deconstrucción de la epidemiologia. Buenos Aires: Lugar Editorial, 2000.

(24) Estar sano no es solamente ser normal en una situación dada, sino también ser normativo en esa situación y otras situaciones eventuales. Lo caracteristico de la salud es la posibilidad de superar la norma que define momentáneamente lo normal, la posibilidad de tolerar infracciones a la norma habitual e instituir nuevas normas en situaciones nuevas. CANGUILHEM, George. Ideologia y Racionalidade nas ciencias da vida. Lisboa: Edições 70.

(25) ECHEVERRIA, R. El búho de Minerva, 3. ed. Santiago de Chile: Dolmen Ediciones, 1997. (26) MATURANA, Humberto; VARELA, Francisco. Op. cit.

(27) Id. Ibid. 
lo contemplaban los sociólogos clásicos"(28). Isto é importante, porque a cada dia aparece com mais força a idéia de primeiro olhar o presente para interpretar a vida dos organismos e populações e explicar a forma como emergem as próprias normas da sociedade, do organismo ou do corpo. Se a norma se localiza na própria vida do organismo e na ação ou vida social, é difícil recomendar que o presente se sujeite a uma imagem do futuro elaborada com qualquer teleologia de tipo cientificista porque para uma projeção onde se põe como eixo a vida, todas as predições se transformam em previsões relativizadas pela força das normas que emergem no presente pela dinâmica da matéria ou pela capacidade autopoiética natural ou social. Assim, unicamente será possivel construir a seguridade do futuro através da ação que se desenvolve aqui e agora ${ }^{(29)}$.

A Saúde Pública Alternativa deve propor uma interpretação diferente, não somente do tempo, mas também do espaço. Tempo e espaço aparecem imbricados na ação humana, onde as noções de presença-ausência humanizam o tempo-espaço. A expressão aqui e agora considera a noção do local como âmbito privilegiado para o pensamento e a prática. $\mathrm{Na}$ localidade seria mais factível descobrir os traços caracteristicos da vida que se tecem como ação social. A Saúde Pública alternativa dá grande ênfase à ação que foi deixada de lado pelo peso avassalador do cogito cartesiano. Além disso, as dicotomias teoria-prática e sujeito-objeto são questionadas e se propõe em que todo conhecer é fazer e todo fazer é conhecer ${ }^{(30)}$, com o que se reconhece que o penso, logo existo é posterior ao ajo, logo existo, conforme propõe Heidegger ${ }^{(31)}$, ou ao distingo, logo existo como fala Von Glaserfeld(32).

A Saúde Pública alternativa nos leva a reconhecer e dar importância a outras racionalidades e nessa empresa, também reconhece que o agir se acompanha de uma consciência prática ${ }^{(33)}$ e portanto, também é racional somente antes que a consciência discursiva se faça presente. Se é assim, então, a saúde se produz dentro da própria racionalidade do agir, com o que a noção promoção ganha uma força inusitada. Não se trata, contudo, apenas da concepção de promover os comportamentos e estilos de vida racionais e universalmente reconhecidos pela epidemiologia ocidental, mas como comportamentos autopoiéticos biológica e culturalmente desenvolvidos pelas próprias populações em seu agir diário. Assim, o caráter civilizatório ou messiânico da ciência ocidental perderia seu poder

(28) GIDDENS, A. Entrevista....

(29) ROVERE, Mario. Planificación Estratégica de Recursos Humanos en Salud. Washington: OPS/OMS, 1993.

(30) MATURANA, Humberto; VARELA, Francisco. Op. cit.

(31) HEIDEGGER, M. El Ser y el Tiempo. México: Fondo de Cultura Económica, 1997.

(32) VON GLASERFELD. Distinguishing de Observer 1999. Disponivel em: http://www.oikos.org/ vonobserv.htm.

(33) GIDDENS, Anthony. Central problems in social theory. Berkeley: University of California Press, 1979. 
autônomo para compartilhar conhecimentos, saberes e práticas com outras culturas ${ }^{(34)}$. A ampliação da razão nos leva, por outro lado, a reconhecer que a verdade científica não é necessariamente boa, mas que o adequado tem que sempre ser sentenciado pela ética (através do acordo intersubjetivo, estabelecemos que é bom para a vida), com o que se estaria justificando a necessidade de uma forte reflexão sobre este tópico ${ }^{(35)}$. Se é verdade que a razão instrumental criada pelo pensamento ocidental já não é aceita como a verdade mas como uma interpretação da realidade, a mesma que será mais facilmente descoberta pelo agir humano diverso, local, complexo e temporal, se conclui que para encontrar a verdade sobre a saúde é fundamental voltar sobre a identidade, sobre o sujeito, sobre o organismo.

É interessante reconhecer que Saúde Pública alternativa proporia compreender a Saúde Pública desde a vida mesma e não somente a partir do cálculo do risco que ocorre por fora e antes que a máquina corporal adoeça. O risco se internalizaria e seria intrínseco à própria vida do indivíduo e do grupo, com o que a Saúde Pública se relacionaria com o intuito de construir a identidade individual e coletiva. Uma das maneiras de promover a saúde se basearia em que a população aprenda a conhecer e manejar os riscos, mais do que querer dominá-lo todo, porque o que com segurança temos aprendido nesta época de inacreditável desenvolvimento científico é que, como haviamos dito anteriormente, existem condições da ação humana desconhecidas e conseqüências da ação não desejadas, em razão do que é mais complexo calcular os riscos manufaturados, sendo mandatório que todos construamos a ação através do acordo intersubjetivo.

O sujeito social e a vida. Nos parágrafos anteriores enfatizamos a necessidade que tem a Saúde Pública de aproximar-se primeiramente da vida e do sujeito, com o fim de se liberar daquela atadura que a obrigava a enxergar apenas objetos alopoiéticos, cifrados pela doença e a morte, os mesmos que deveriam ser exorcizados por uma Saúde Pública cientificista e normativa montada no aparato Estatal. Imaginar que a saúde ocorre pelo próprio fato ou ação de viver é, sem dúvidas, refrescante, porque realça o caráter autopoiético do ser vivo. Ao mesmo tempo, é perigoso que esse pensamento, livre de qualquer amarra, nos leve a gerar imagens de organismos particulares que supostamente existem à margem do sistema social, quando sabemos que a Saúde Pública, ao tentar compreender a saúde como fato social, tem que, necessariamente, interpretar o viver como ação biológica e social. Mas isso não é suficiente. A Saúde Pública enquanto multidisciplina não pode compreender somente as ações sociais que geram saúde, mas deve, também, explicar e traba-

(34) GONZÁLEZ, M. Educación, Universidad y Postmodernidad - Poligrafiados de la UNL, Loja, 1999.

(35) Los trabajos de Berlinguer y Garrafa sobre ética son de gran importancia. El Programa de Bioética de la OPS han apoyado grandemente el tratamiento de este tema. El que escribe, también ha realizado un módico aporte en el artículo El Sujeto, la Ética y la Salud. 
Ihar sobre as estruturas que potencializam ou restringem o desenvolvimento dessas ações sociais. Nessa medida, a Saúde Pública deve visar a ação e a estrutura. Não pode, entretanto, ver a ação de viver unicamente desde a estrutura porque terminaria traduzindo-a em uma simples função tal como fez o pensamento funcionalista sobre o qual se fundamentou a Saúde Pública convencional. Tampouco pode ver a estrutura unicamente desde a ação, porque terminaria interpretando que a estrutura é somente um epifenômeno da ação.

A Saúde Pública Alternativa exige que se entenda a estruturarão das práticas sociais saudáveis e deletérias, isto é, que se compreenda e explique como a estrutura é constituida pela ação e, reciprocamente, como a ação é constituída estruturalmente ${ }^{(36)}$. Nessa medida poderemos interpretar que a vida saudável é construída diária e ativamente pelos sujeitos aptos e qualificados, mas que ao mesmo tempo fazem essa construção como atores historicamente situados e não sob condições de sua própria eleição ${ }^{(37)}$. Assim, as condutas saudáveis podem ser interpretadas tanto como ações intencionais geradas pelo sujeito e também, ao mesmo tempo, habilitadas ou constrangidas pelas regularidades estruturais em que desenvolve dito comportamento. Os mencionados processos de estruturação das práticas sociais saudáveis ou deletérias deverão, necessariamente, ser entendidos com base na interação de marcos significativos constituidos pelos próprios atores sociais, marcos que se sustentam em critérios de verdade, eticidade e veracidade. Esses, por sua vez, se desenvolvem veiculados por poderes que se reproduzem nessa interação. Giddens opina que toda ordem cognoscitiva e moral é ao mesmo tempo um sistema de poder, que inclui um horizonte de legitimidade ${ }^{(38)}$. Desta forma a Saúde Pública poderia resistir à receita reducionista da razão instrumental, que intenta ver a ação humana como uma simples função da estrutura, para melhor resgatar as práticas sociais com suas potencialidades emancipadoras.

A Saúde Pública Alternativa manifesta seu compromisso de impulsionar a estruturação de práticas saudáveis com a participação dos distintos atores sem deixar de lado o estudo do sistema, enquanto normas e recursos, que apóiam ou perturbam o desenvolvimento de ações saudáveis. É por isto que haviamos dito que o trabalho do sanitarista se centra sobre a interpretação das ações vitais que geram saúde e, ao mesmo tempo, a mediação promotora de normas e recursos que realizam dito trabalho, mas que, em nenhum momento, cremos que é conveniente somente centrar-se sobre as funções estatais. As Funções Essenciais da Saúde

(36) GIDDENS, Anthony. New Rules of Sociological Method. 2. ed. Stanford: Stanfor University Press, 1993.

(37) MARX, Carlos. El Dieciocho Brumario. México: Editorial Cartago, 1972.

(38) GIDDENS, Anthony... cit. 
Pública recomendadas pela Organização Panamericana de Saúde ${ }^{(39)}$ conduzem a visualizar as obrigações de um Estado que havia deixado de lado o trabalho neste campo, não dando conta das mudanças urgentes que se devem levar a cabo nos modos de ver, interpretar e agir na Saúde Pública. Isso porque, ao centrar a preocupação sobre o trabalho governamental, as práticas sociais que podem apontar para a saúde e a vida são conceitualizadas com bastante profundidade, mas logo passam a ser operacionalizadas enquanto função estatal. Em outras palavras, as Funções Essenciais da Saúde Pública parece que estariam interpretando que somente é possivel alcançar a vida e a saúde por meio do controle do Estado no momento de sua imensa debilidade. Quem sabe, a possibilidade de que o Estado não diminua ainda mais suas obrigações sociais sobre a saúde repousa em que as novas forças ou movimentos sociais possam ampliar a democracia mas, ao mesmo tempo, fortaleçam sua capacidade de controle social, vigilância e pressão sobre os deveres do Estado no âmbito da saúde coletiva. Como disse Amelia Cohn ...continuamos condenados(as) a buscar decifrar as novas formas de construção e mediação entre interesses particulares e universais, sem cair nas artimanhas de retomar a velha antinomia entre Estado e sociedade civil, e tampouco confundir o público com o estatal... não ceder os preceitos e valores éticos comprometidos com a democracia sem perder a perspectiva crítica que tal opção exige. ${ }^{(40)}$

\section{A INTERPRETAÇÃO-AÇÃO}

É fundamental que compreendamos as linguagens da vida natural. Nesse campo tanto a ecologia como a biologia tem avançado significativamente na compreensão da vida como autopoiese, relação em redes autodependentes, sistemas complexos, etc., avanços que em alguma medida se vão integrando à Saúde Coletiva e que nos brindarão novos elementos para uma melhor compreensão do complexo mundo da vida(41). Além disso, é fundamental que recordemos que o agir no campo da Saúde Pública, conforme reconhece Mario Testa ${ }^{(42)}$, se desenvolve em um duplo movimento de determinação-constituição e de significado-sentido. Em outras palavras, é fundamental que a ação em Saúde Pública opere com

(39) ORGANIZACIÓN PANAMERICANA DE LA SALUD. Las funciones esenciales de la Salud Pública. Washington: OPS/OMS, 2002.

(40) COHN, Amelia. Estado e sociedade e as reconfiguraçōes do direito a saúde. Ciência e Saúde Coletiva, v. 8, n. 1, p. 9-32, 2003.

(41) Los aportes de Humberto Maturana, Francisco Varela, Fritjof Capra, etc. son posiblemente los que más apoyan para establecer una potencialidad interpretativa diversa para la Salud Pública.

(42) TESTA, Mario. Saber en Salud: la construcción del conocimiento. Buenos Aires: Lugar Editorial, 1997. 
um critério de busca das determinações de seu objeto de estudo, isto é, descubra as "forças positivas que estabelecem os limites dentro dos quais pode ocorrer o fenômeno". Além disso, na ação em Saúde Pública o sanitarista se constrói enquanto sujeito, passando por sujeito da vida, sujeito epistêmico (cognitivo), sujeito público para, por último, reconstituir-se como sujeito da vida comprometido com a mudança requerida. Para fazê-lo o sanitarista deve compreender e explicar o mundo de significado com o que se encontra e que, em geral, se consolida enquanto estrutura. Ele deve, também, buscar construir o mundo de amanhã com um sentido definido. O jogo de sentido-significado-determinação-constituição é um jogo complexo capaz de caminhar com algum êxito entre o scila do subjetivismo e o caribdis do objetivismo. A respeito de tal exigência, Mario Testa reconhece a necessidade de uma dupla hermenêutica recomendada por Habermas e Giddens. A esse respeito as ciências sociais, como dissemos, têm avançado muito e propõem ser necessário levar a cabo uma dupla hermenêutica. Uma primeira hermenêutica através da imersão direta do cientista social com a população e em seu mundo da vida, com o que se defende o caráter sempre qualificado que detém todo o membro da população para forjar suas próprias verdades, eticidades, veracidades, práticas e estratégias de organização de seu poder. Mas, além disso, as ciências sociais defendem a necessidade de uma segunda hermenêutica, com vistas a enriquecer aquela vida social com a contribuição das possibilidades explicativas da ciência.

O mundo em que se move o sanitarista é um mundo que está dado(43) e que também está se dando. Está dado como estrutura na qual é possivel encontrar recursos físicos, ecológicos, biológicos, financeiros, tecnológicos etc. por um lado, mais, também, normas: leis, regulamentos, diretrizes reconhecidas e institucionalizadas. Está, além disso, dando-se (ocorrendo) como a autopoiesis vital individual e social e como produto do agir das pessoas com suas verdades, eticidades, veracidades, práticas e estratégias de organização de seu poder. O sanitarista precisa conhecer agir nesse mundo duplo, do dado e do dando-se. A complexidade da açãoinvestigação por parte do sanitarista resulta de que se aproxima no mundo do dado a um objeto que aparece como biopsicologia individual, que também é social por seu acoplamento estrutural e consensual de que nos fala Maturana ${ }^{(44)}$. Portanto, o sanitarista lida com um objeto que sempre é sujeito. Não é apenas social, mas está constantemente dando-se, ou seja, é uma biopsicologia individual que está dando-se por própria autopoiesis individual e pela inter-relação social. Em outras palavras, trabalhamos sempre com objetos que são sujeitos e com individuos que são sociais, mas que nunca perdem seu caráter individual, por sua caracteristica autopoiética, conforme indica Castiel ${ }^{(45)}$.

(43) ZEMELMAN, Hugo. Los horizontes de la razón. t. 1. México: Antropos, 1992.

(44) MATURANA, Humberto; VARELA, Francisco. Op. cit.

(45) CASTIEL, David. Op. cit. 
Tal situação complica ainda mais a efectividad operacional en el dominio de la existencia ${ }^{(46)}$ (conhecimento) do sanitarista, porque não apenas deve conta de um objeto-sujeito que está se dando enquanto ator social, senão que deve, também, dar conta de um ator sócio-biológico. Em outras palavras, deve imbricar a aproximação que propõe Testa com aquele olhar do epidemiólogo, conforme reclama Almeida Filho ${ }^{(47)}$ em sua obra "A ciência tímida". Não é suficiente, entretanto, que o sanitarista se aproxime do ator sócio-biológico para compreendê-lo. É necessário, também, que compreenda que o ator sócio-biológico deve alcançar sua constituição como tal durante a própria inter-relação. Esta última exigência é abordada por Ayres $^{(48)}$, que, por sua vez, recomenda uma aproximação regida pelo conceito cuidado para alcançar aquilo que ele denomina alcance prático, em contraste como êxito técnico que aparece como unilateral e incompleto. Testa, por sua vez, nos fala da necessidade de uma aproximação amorosa. Em outras palavras, a Saúde Coletiva ou Saúde Pública Alternativa estaria buscando que aquele caminho trágico para a humanidade, - de que nos fala Madel Luz - em que verdade e paixão, razão e emoção, sentimentos e vontade, beleza e sentidos se deram adeus, se voltem a encontrar agora ${ }^{(49)}$.

Frente a complexidade da ação-conhecimento por parte do sanitarista é fundamental, então, recorrer àquela dupla hermenêutica de que nos fala Mario Testa, começando pela hermenêutica 0 (zero) centrada na linguagem para logo passar a uma hermenêutica 1 (um), onde as diferentes lógicas científicas respondem bem às exigências do conhecer-fazer. Em outras palavras, parece que a Saúde Pública alternativa nos está ensinando que não é possivel apoiar todo o conhecimento da complexa problemática em modelos explicativos matemáticos. É fundamental sua simbiose com modelos compreensivos que possibilitem a recuperação do humano frente à sua naturalização, implementada pelos discursos da medicina e da saúde pública tradicional, ou a eliminação do sujeito individual e social frente à necessidade de condicioná-lo à suposta verdade de certos discursos científicos sociais e politicos sustentadas por algumas versões da Epidemiologia Crítica, como aquela em cujo desenvolvimento participei, quando trabalhei - na década dos 80 - no Centro de Estudios y Asesoria en Salud, CEAS, do Ecuador ${ }^{(50)}$.

(46) MATURANA, Humberto; VARELA, Francisco. Op. cit.

(47) Las teorias contemporáneas de la planificación - gestión en salud son cada vez más basadas en el concepto práctica, todavia se las aplican sin el instrumental de la epidemiologia, como si la epidemiologia no tuviera nada que decir a los planificadores de las escuelas de Carlos Matus o Mario Testa... ALMEIDA FILHO Naomar. Op. cit.

(48) AYRES, José Ricardo. Conceptos y prácticas en salud pública: algunas reflexiones. Revista Nacional de Salud Pública, v. 20, n. 2, p. 67-82, 2002.

(49) LUZ, Madel. Op. cit., p. 8.

(50) GRANDA, Edmundo y BREILH, Jaime. Saúde na sociedade. 2. ed. São Paulo: ABRASCO, 1989. 
A proposta da epidemiologia dos modos de vida, os modelos de fragilização e a etnoepidemiologia que apresenta Naomar Almeida na Ciência Tímida, possibilitaria à Saúde Pública Alternativa interpretar a doença na população como um processo histórico, complexo, fragmentado, conflitivo, dependente, ambíguo e incerto, conforme propõe o autor, permitindo, ao mesmo tempo, a projeção de uma ação mais precavida que preditiva. Nesse campo, a Saúde Pública alternativa também nos está levando a pensar que é fundamental superar as formas de validação redutoras que atribuem a realidade fundamental e a eficácia causal ao mundo das matemáticas, identificado como o reino dos corpos materiais que se movem no espaço e no tempo(51), que entrega, como disse Ayres, um imenso peso ao ser dos objetos e à transcendência do conhecimento, negando, ao mesmo tempo, o ser do homem e a transcendência do mundo. Proporiamos, conforme sustenta o autor, que a verdade e pertinência do que fazer da Saúde Pública sejam julgadas com base na configuração de projetos sociais para o conhecimento e transformação da realidade que se constroem e se transmitem intersubjetivamente em forma de normas que conseguem se tornar válidas para o conjunto da sociedade ${ }^{(52)}$.

A Saúde Pública Alternativa que se quer desenvolver exige transformações no âmbito da formação do pessoal. A formação do sanitarista adequado para a metáfora da enfermologia pública se relacionava com uma imagem do sanitarista interventor técnico-normativo, enquanto que o momento atual reclama, como dissemos, um sujeito intérprete-mediador, ou seja: intérprete dos modos como os atores individuais e sociais, em seu viver diário, constroem seus saberes, desenvolvem as ações relacionadas com a promoção de sua saúde e cuidam de sua doença; e, mediador estratégico com os poderes científico, politico e econômico para apoiar a elevação dos níveis de saúde e vida. Primeiramente, a formação do sanitarista tentaria dar conta daquele descuido da Saúde Pública pela saúde e traria elementos filosóficos, teóricos, metodológicos e técnicos para a interpretação da saúde. Ao mesmo tempo, porém, estaria reconhecendo a necessidade de apoiar a compreensão por parte dos estudantes de que uma força fundamental para a produção da saúde e para controlar socialmente o exercício econômico, técnico e politico do sistema se encontra na própria forja dos públicos pela saúde. Como segunda característica, a formação do profissional tentaria dar uma resposta diferente face às mudanças que vivemos, isso é: estabelecer como eixo a vida e o agir do povo para entender e mobilizar os conhecimentos científicos e não-científicos existentes, viabilizar as forças políticas e encaminhar os recursos necessários para melhorar a saúde e a vida das pessoas. Essa ação mediadora obriga, por outro lado, as instituições formadoras de sanitaristas a manter uma posição ética de defesa da vida, a eqüidade e a

(51) BURTT, E. A. (org). The Englixh Philosophers from Bacon to Mill. Mencionado por Ayres José Ricardo. Epidemiologia e Emancipação, cit., p. 74.

(52) AYRES, José Ricardo. Epidemiologia e emancipação, cit., p. 79. 
construção de uma nova cidadania. Exige, também, adotar uma atitude reflexiva a respeito de nossas próprias capacidades de conhecer e agir, e sobre o uso da ciência e da tecnologia.

\section{O QUE É A SAÚDE COLETIVA HOJE?}

Jairnilson Silva Paim e Naomar de Almeida Filho definem a Saúde Colectiva como um conjunto articulado de práticas técnicas, ideológicas, políticas e econômicas desenvolvidas no âmbito acadêmico, nas instituições de saúde, nas organizações da sociedade civil e nos institutos de pesquisas informadas por distintas correntes de pensamento resultantes da adesão ou crítica aos diversos projetos de reforma em saúde ${ }^{(53)}$...a Saúde Coletiva se consolida como campo científico e âmbito de práticas aberto à incorporação de propostas inovadoras. Não creio que exista discussão sobre essa definição. O desafio que temos em nossos países é, como disse, transcender a teoria e prática convencional da saúde pública com vistas a desenvolver as melhores idéias e ações para apoiar a forja de uma Saúde Pública que possa interpretar e mediar com conhecimento e eficácia na melhora e cuidado dos niveis de saúde da população. Quando tentamos cumprir essa missão, os frutos, maduros uns, verdes outros, e em gestação alguns, pertencentes à árvore da Saúde Coletiva, alimentam e dinamizam a empreitada.

A Saúde Coletiva como campo de conhecimento em constante desenvolvimento constitui, em primeiro lugar, um ponto de referência obrigatório e de reflexão para ampliar os horizontes de visão do objeto problema saúde-doença-cuidado das populações. Ao me referir à ampliação da visão, falo dessa necessidade de ver a saúde populacional em sua realidade histórica, em sua matriz contextual, em sua fundamentação vital e não somente como subtração da doença. O desafio de criticar, conservar e superar a saúde pública convencional, não se baseia apenas na possibilidade de ampliar os horizontes de visão, mas, ao mesmo tempo, mudar as práticas que buscam unicamente êxito técnico para que passem a buscar o alcance prático, ou seja, exercer o dever e o direito de cuidar de nosso povo. Ao fazê-lo, desenvolver o quádruplo movimento, que nos recomenda Testa, de construção de sentido e significado, de constituição e determinação, compreendendo, além disso, que ele acontecerá sempre e quando os atores individuais e sociais se constituam igualmente em sujeitos que constroem sua saúde se enriquecendo com o aporte científico que traz a Saúde Coletiva, exercendo seu poder e direito enquanto cidadãos. Para ele, então, a dupla hermenêutica é fundamental, tanto quanto o aporte da experiência vivida pela militância sociopolítica da Saúde Coletiva.

(53) PAIM, J. Silva; ALMEIDA FILHO, Naomar. A Crise da Saúde Pública e a utopia da saúde coletiva. Salvador: ISC-UFBA, 2000. 
Além de se preocupar com reconceitualizar e mudar a interação interventora técnico-normativa no campo da enfermologia pública, a Saúde Pública alternativa deve, necessariamente, estabelecer uma projeção e relação diferente com as politicas, estruturas e instituições existentes no campo, com vistas a alcançar maiores doses de democracia, eficácia e eqüidade. Isso não pode, contudo, ser alcançado por meio de versões interventoras de velho ou novo cunho, se não por meio da construção de povos que protegem e desenvolvem suas instituições e controlam o cumprimento das obrigações estatais em saúde. Novamente as experiências vividas por gerentes e governantes procedentes da Medicina Social latinoamericana e da Saúde Coletiva são indispensáveis. A tentativa de emigrar da enfermologia pública para uma proposta alternativa em Saúde Pública tem-se constituido em um processo complexo para a Universidade Nacional de Loja, tanto quanto para qualquer ator que queira enfrentar esse desafio com responsabilidade. No âmbito disciplinar, a imbricação do planejamento e da gestão com a epidemiologia constitui possivelmente o problema metodológico mais complexo, sobre o qual já brilham algumas luzes, por meio das propostas de sintese produzidas na área. O diálogo entre as ciências da saúde dominadas pelo discurso médico e da doença e o discurso das ciências sociais tem avançado, mas deve seguir adiante, superando os múltiplos problemas como, por exemplo, aqueles apontados por Maria Cecilia Minayo e colaboradoras(54). A ampliação e complexização do campo também assusta a muitos e causa reação negativa de outros, na medida em que provimos de uma área tradicional da saúde pública, onde a repetição de mais do mesmo constitui, em geral, a norma. A formação de recursos humanos nesse âmbito interdisciplinar choca-se contra a forma utilitarista e tecnicista da educação anterior.

O que é a Saúde Coletiva, hoje? Creio que um esforço decidido para enxergar mais além do horizonte que legou a Saúde Pública convencional; é uma profunda vocação para transformar nossa ação em um que fazer humano profundamente comprometido com a vida e com o cuidado da enfermidade de nossas populações (uma militância socio-política, nas palavras de Testa); é uma tentativa de nos construirmos como sujeitos sanitaristas, em função de respeitar individualidades e apoiar a construção de cidadãos; é uma tentativa de criar espaços de aprendizagem para multiplicar as forças do compromisso; é buscar o desenvolvimento das ciências da saúde para com elas potencializar o desenvolvimento da saúde e a felicidade, assim como a diminuição do sofrimento dos enfermos e controlar as doenças controláveis; é o empenho para que nossas instituições tenham a nossa cara, apesar de que a cada dia nos queiram convencer de que não vale a pena o humano. Essa coisa chamada Saúde Coletiva, é algo que vale a pena acalentar e estimular seu crescimento, porque, em última instância, é acreditar naquilo que é uma grande realidade: a solidariedade para gerar o mundo que sonhamos.

(54) MINAYO, Maria Cecilia y col. Posibilidades e dificuldades nas relações entre ciências sociais e epidemiologia. Ciência e Saúde Coletiva, v. 8, n. 1, p. 97-100, 2003. 


\section{REFERÊNCIAS BIBLIOGRÁFICAS}

ALMEIDA FILHO, Naomar. La ciencia tímida: ensayos de deconstrucción de la epidemiología. Buenos Aires: Lugar Editorial, 2000.

; PAIM, J. Silva. "La crisis de la salud pública y el movimiento de salud colectiva en Latinoamérica". Cuadernos Médico Sociales, vol. 75, p. 5-30.

AROUCA, Sergio. O dilema preventivista: contribuição para a compreensão e crítica da medicina preventiva. Tese (Doutorado) Universidade de Campinas, Campinas.

AYRES, José Ricardo. "Conceptos y prácticas en salud pública: algunas reflexiones". Revista Nacional de Salud Pública, vol. 20, n. 2, p. 67-82, 2002.

Abrasco.

. Epidemiologia e emancipação. Rio de Janeiro: Hucitec;

CANGUILHEM, George. Ideología y racionalidade nas ciencias da vida. Lisboa: Edições 70.

CASTIEL, David. O buraco e o avestruz: a singularidade de adoecer humano. Campinas: Papirus, 1994.

COHN, Amelia. "Estado e sociedade e as reconfigurações do direito a saúde". Ciência e Saúde Coletiva, vol. 8, n. 1, p. 9-32, 2003.

ECHEVERRÍA, R. El búho de Minerva, $3^{a}$ ed. Santiago de Chile: Dolmen Ediciones, 1997.

FOUCAULT, Michel. El nacimiento de la clínica. México: Siglo XXI, 1966. GIDDENS Anthony. Central problems in social theory. Berkeley: University of California Press, 1979.

New rules of sociological method, $2^{\text {a }}$ ed. Stanford: Stanfor University Press, 1993.

GONZÁLEZ, M. "Educación, universidad y postmodernidad". Poligrafiados de la UNL, Loja, 1999.

GRANDA, Edmundo. "Salud: globalización de la vida y de la solidaridad". Saúde em Debate, vol. 24, n. 56, p. 83-101.

"La salud pública y las metáforas sobre la vida". Revista de la Facultad Nacional de Salud Pública, vol. 18, n. 2, p. 83-100, jul./dic. 2001. . "Sujeto, etica y salud". Salud Pública Experiencias y Reflexiones, n. 3, p. 46-61, 1997.

y col. "Salud pública: hacia la ampliación de la razón". In: La medicina al final del milenio. Guadalajara: Universidad de Guadalajara, 1995.

; BREILH Jaime. Saúde na sociedade, $2^{\underline{a}}$ ed. São Paulo:

ABRASCO, 1989. 
HABERMAS, Jurgen. Teoría de la acción comunicativa. Madrid: Taurus, 1992.

HEIDEGGER, M. El ser y el tiempo. México: Fondo de Cultura Económica, 1997.

LUZ, Madel. Natural, racional, social. Buenos Aires: Lugar Editorial, 1997. MARX, Carlos. El dieciocho brumario. México: Editorial Cartago. 1972.

MATURANA, Humberto y Varela Francisco. El árbol del conocimiento. 9. ed. Santiago de Chile: Editorial Universitaria, 1993.

MINAYO, Maria Cecilia y col. "Posibilidades e dificultades nas relações entre ciências sociais e epidemiologia". Ciência e Saúde Coletiva, vol. 8, n. 1, p. 97-100, 2003.

Organización Panamericana de la Salud. "La crisis de la salud pública". Washington D.C.: OPS/OMS, 1993.

OPS/OMS, 2002.

Las funciones esenciales de la Salud Pública. Washington:

PAIM, J. Silva; ALMEIDA FILHO, Naomar. A crise da saúde pública e a utopia da saúde coletiva. Salvador: ISC-UFBA, 2000.

PASSOS, Nogueira Roberto. Perspectivas da qualidade em saúde. Rio de Janeiro: Qualitymark, 1994.

ROSEN, George. Da polícia médica a medicina social. Rio de Janeiro: Ed. Graal, 1979.

ROVERE, Mario. Planificación estratégica de recursos humanos en salud. Washington: OPS/OMS, 1993.

TESTA, Mario. Pensar en salud. Buenos Aires: Lugar Editorial. 1993.

. Saber en salud: la construcción del conocimiento. Buenos

Aires: Lugar Editorial, 1997.

VON GLASERFELD. "Distinguishing de observer". 1999. Disponivel em: $<$ http://www.oikos.org/vonobserv.htm>.

ZEMELMAN, Hugo. Los horizontes de la razón. México: Antropos, 1992. t. 1. 